
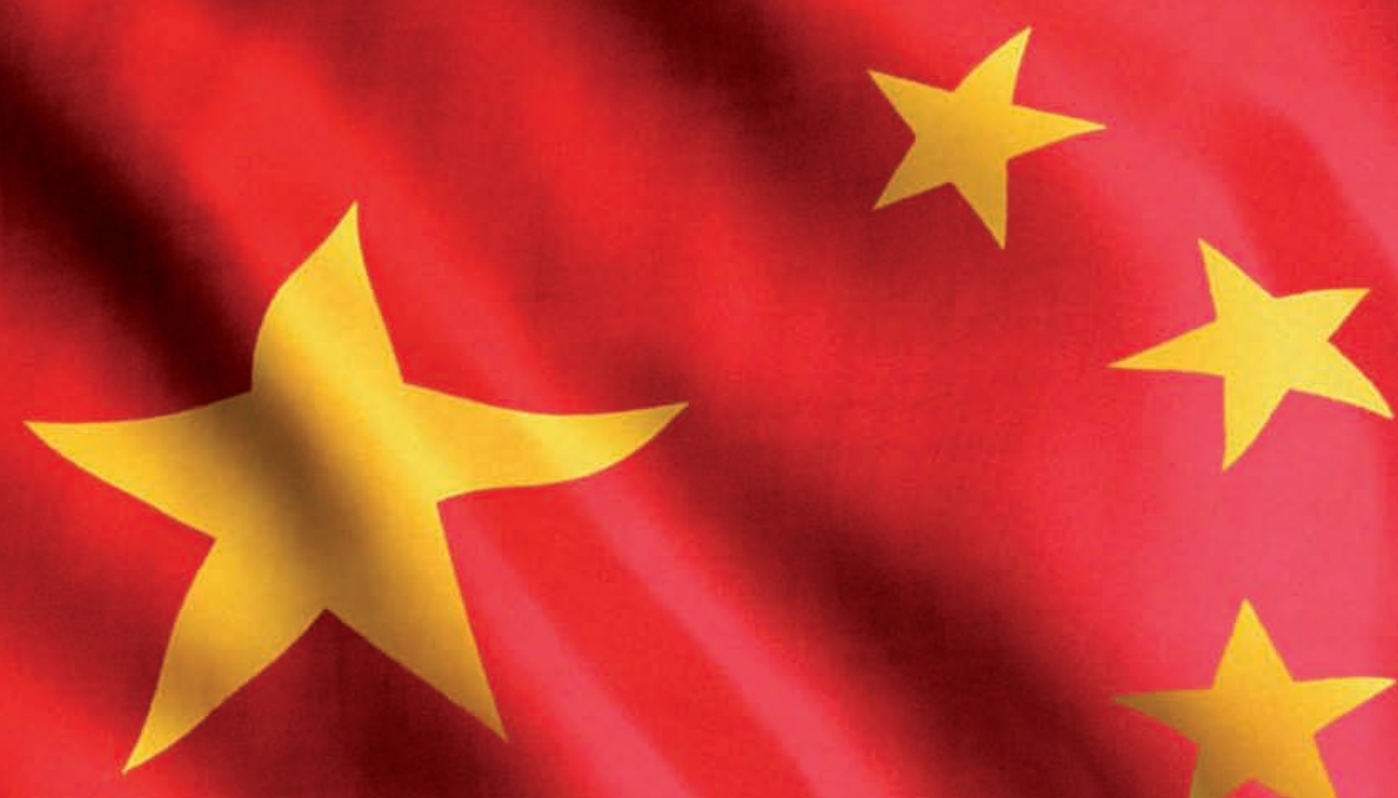

Oe

\section{Cómo nos afecta lo que pasa en China}

Por primera vez se observa una posible desaceleración de la economía china. Ella solía ser el motor que quedaba funcionando cuando Europa, Japón, o Estados Unidos caían. ¿Qué nos podría pasar en este escenario? Por Carlos García*
Chile, 2012. ¿Se repetirá el crecimiento 2011 o la economia se estancará como Si consideramos los últimos datos de inflación, crecimiento (medido por el IMACEC) y desempleo, la economia chilena se estaria acercando a su pleno empleo: una situación donde más demanda bienes y servicios causara mas inflación y por tanto el Banco Central de Chile se verá obligado a subir la tasa de interés
de politica monetaria sin importar si los de pollica monetaria sin importar si los en productos básicos como los alimentos. Los efectos de este escenario también se traducirian en un tipo de cambio más bajo. En efecto, las mayores tasas atraerían capitales externos, los cuales presionarian, por la mayor oferta de dólares, hacia una caída del precio del dólar. Acaso estos son los problemas que una economía quiere tener. Sin embargo existe un escenario alternativo relacionado son el desempeño de la economia mundial, y fundamentalmente con China. Si el crecimiento chino cae -por la meno actividad económica en Europa y Estados unidos-, entonces Chile deberá moderar de estos meses terminar tos resulta dos del IMACEC serán cada vez peores, aumentará la tasa de desempleo y el IPC registrará cifras bajas. El Banco Centra deberá bajar tasas y con ello el precio del dólar subirá. Como se puede aprecia los dos escenarios son completamente opuestos: en uno la economia entra de lleno a una senda de expansión y buenas noticias, en el segundo la situación es bastante más sombría.
En ambos casos se juegan muchas cosas que no marcarán los años por venir En lo político, en el escenario más negativo para la Alianza, ella podria perder moortantes candidatos en las próximas elecciones municipales y ver complicada la reeleccion de uno de sus candidatos para las elecciones presidenciales de unce peora au si las ruación económica emson causadas por una de este deterioro sońs deprimida y no tienen que ver directamente con las politicas del gobierno Por el contrario, una economia boyante puede asegurar un segundo término para a a alianza y entonces el futuro político depende completamente de la capacidad del gobierno de aprovechar la situación. Sin embargo un tema que puede amagar las posibilidades de la Alianza en las próximas elecciones bajo este escenario positivos son las mayores demandas sociales. En efecto, como ha ocurrido en el caso de Aysen o las protestas estudiantiles, un buen mona económico es también un pos de interés presion diferentes grusu favor. Chile es un pas con importantes inequidades que posibiton et suramiento de demandas de personas que se sienten excluidas del crecimiento económico que han experimentado los sectores más modernos y con mejores salarios (financiero, minero, etc) o de aquellas regiones menos beneficiadas con respecto a otras (el extremo sur en relación a las regiones mineras y a Santiago). economia mundial especialmente por 10 
que está ocurriendo en China. La diná- materias primas cuyos precios dependen mica en los últimos años ha estado mar- de la demanda de otros paises. Seria ilucada por lo que ocurra en ese pais. Una so creer que la econd
fracción importante de los productos se forma autónoma.

ha concentrado en esa economía, no solo para el consumo externo sino tambien para el consumo interno. Con el correr de los años, y más que otras potencias eco-
nómicas emergentes como India, Brasi y Rusia, el gigante oriental ha resultado y Rusia, el gigante oriental ha resultado que fallen otros bloques económicas, (n) y la capacidad para satisfacer la demanda mundial de un sinnúmero de productos ha terminado por ubicar a China en una posición clave. Su consumo de petróleo que un estornudo de esta economía hace que los precios de productos clave suban bajen en forma dramática.

Dadas las dimensiones de la economia China, una desaceleración es un indica-
dor claro de que la economia mundial se dor claro de que la economia mundial se
resentirá. Por supuesto, con esto la economia chilena también se desacelera. Hay que recordar que la economía mundia que involucran no solo el comercio de bienes, sino también los flujos de capita les. Si China no crece a las tasas espera das, el resto de las economias - un frág Estados Unidos, un Japón estancado y una Europa en recesión-, deberá reduci la dependencia de la economía chilen a la economia internacional, no hay otra
opción. Somos productores de muchas conomia pueda crecer en enario, relativamente novedoso puesto que China viene creciendo fuerte hace tres décadas, las opciones no son las mas optimistas. ¿Cuál será la eaccion de los inversionistas si China se deolita? Es un misterio; una posibilidad que hasta ahora nadie habla considerado, quizas porque aun creemos que Chieso dejó de ser verdad hace varios años. La realidad es que China es capitalista y por lo tanto estará sujeta a las misma fluctuaciones que las otras economias de este tipo, nos guste o no.

China se está desacelerando. Por lo tanto, eso afectará la travectoria del precio de muchos productos, entre ellos e cobre. Una buena noticia es que el menor crecimiento de China reducirá la presión sobre el petróleo y dará un respiro a nuestra industria y a las familias. Po supuesto, lo que suceda con China no es coridades de ese pais, porque las autodo lo posible por que el crecie de hacer su economia siga fuerte: bajaran sus tasas de interés mantendrán el dólar alto invectarán más gasto fiscal. Recordemos que la situación social en China, como en muchas naciones emergentes, también es frágil, en especial en los malos tiempos. Solo basta pensar la presión que pueda causar algunos puntos más de desempleo en la sociedad China, donde están obligados a tener altas tasas de crecimiento para hacer sostenible su estándares de la politica fiscal, en especial la reforma vida, que si bien son moderados, deben tributaria. ¿Es momento para discuti de personas. er. Si las economias más desarrosubir los impuestos a las empresas? Si se escenario menos favoraaconsejable. Sin duda que la inversión Sele que produce de todo para elas, deberia tamien tener problemas similares. NNo mas altos. La prescripcion en este caso es sit por hablando de una recesion, pero postergar unos meses la discusion tributaNo cremos, de un menor dinamismo. ra hasta que se despeje la incertiaumbre sobre el futuro de la economia. En caso contrario, se puede correr el riesgo de que vea afectada por la coyuntura: Io menos recomendable para una reforma que buslas que vienen de materias primas. Las combustibles y otros productos deberán suavizarse. públicas. Por otro lado, el gasto fiscal debe mantenerse pero con la posibilidad de aumantenerse pero con la posibiliaad de aucaso que la situación empeore.

Reformas más especificas como mejoramientos en la competencia, fiscalitual requiere una división entre politicas macroeconomicas y sectoriales. Desde e punto de vista macroeconómico, el Banco Central de Chile debe estar atento a no reaccionar en exceso, y por tanto a no sucaida del precio del dólar, lo que debilita sector exportador en caso que a débil demanda mundial deprima o por primas por debajo de los niveles del año pasado. En las actuales circunstancias ent BCCh ha sido consciente de la enorme incertidumbre que rodea a la economía chilena, y ha seguido una politica monetari ciones entre empresas y trabajadores, y los asuntos medio ambientales deben segui asuntos medio ambientales deben seguir
su proceso, pero con precaución. Mantesu proceso, pero con precaucion. Mante-
ner altas las expectativas de los empres ros debe ser clave en la actual situacion. s bien son requisitos de largo puza inportantes para nuestra largo plazo impueden ir en la dirección contraria a la deseada si en el corto plazo las empresas enfrentan problemas coyunturales. Tanto este tema como en la posible reforma tiutaria, la graduación es un variable clave ra evitar reacciones del sector privedo

Un campo más complejo se encuentra que puedan empeorar la situación. 